\title{
SERAT WEDDHAKARANA: PANDUAN MERAIH KEINGINAN DALAM BUDAYA JAWA
}

\author{
Rahma Qori Fadzilah $^{1}$ dan Venny Indria Ekowati ${ }^{2}$ \\ Prodi Pendidikan Bahasa Jawa, Fakultas Bahasa dan Seni, Universitas Negeri Yogyakarta \\ rahmaqori10@gmail.com¹ dan venny@uny.ac.id ${ }^{2}$
}

\begin{abstract}
Abstrak
Penelitian ini bertujuan untuk mendeskripsikan naskah, membuat transkripsi, membuat transliterasidan menyajikan suntingan teks, serta membuat terjemahan teks. Selain itu, juga mendeskripsikan ilmu firasat yang terkandung dalam teks Sêrat Weddhakarånå. Penelitian ini dilakukan dengan menggunakan metode deskriptif dan filologi modern. Sumber data penelitian ini adalah naskah Sêrat Weddhakarånå yang disimpan di perpustakaan Balai Bahasa Yogyakarta, dengan nomor koleksi R00762. Teknik pengumpulan data dilakukan dalam beberapa langkah, yaitu 1) inventarisasi naskah, 2) deskripsi naskah, 3) transkripsi teks, 4) transliterasi, 5) suntingan, 6) terjemahan, dan 7) pemaknaan teks. Data dianalisis dengan menggunakan teknik analisis deskriptif. Validitas data dilakukan dengan menggunakan validitas semantik. Reliabilitas yang digunakan, yaitu interatter dan intraratter.Namun pada artikel ini hasil penelitian filologi tidak disampaikan secara lengkap karena keterbatasan halaman. Hasil penelitian terhadap naskah Sêrat Weddhakarånåmenunjukkan bahwa kondisi naskah Sêrat Weddhakarånå keadaannya masihterawat, tulisannya jelas, dan mudah dibaca. Isi Sêrat Wéddhåkarånåberdasarkan hasil penelitian sebagai berikut: terdapat sebab-sebab tercapainya keinginan yaitu diinginkan, difikirkan dan dilaksanakan. Selain itu agar keinginan itu terwujud, ada beberapa hal yang harus dijaga dan diusahakan menurut Sêrat Wéddhåkarånå yaitu kesehatan, ilmu pengetahuan dan ketrampilan, dan watak kelakuan baik. Beberapa hal tersebut harus dilakukan bersama-sama agar keinginan yang diharapkan dapat terwujud. Yang terakhir adalah cara-cara meraih kemuliaan dan keberuntungan menurut Sêrat Wéddhåkarånå itu ada dua. Yang pertama menurut hal gaib atau samar yaitu sebab kemuliaan dan keberuntungan adalah hasil dari perbuatan yang sudah dilalui sebelumnya, yang dinamakan beruntung itu merupakan mendapatkan sesuatu yang bukan dari hasil perbuatan yang dilaluinya, itu merupakan hadiah yang tidak disangka-sangka. Jadi jika manusia tidak mendaptkan keberuntungan dan kemuliaan tidak boleh mengeluh. Yang terakhir adalah sebab kemuliaan dan keberuntungan yang bisa dinalar yaitu berasal dari watak yang baik. Watak baik seperti rajin, berhati-hati dalam bertindak, pintar, serta bisa baik dalam pergaulan terhadap sesama.Keenam, membahas sebab-sebab tercapainya keinginan, bagaimana terwujudnya keinginan serta tata cara meraih keberuntungan dan kemuliaan.
\end{abstract}

Kata kunci : Sêrat Wéddhåkarånå , keinginan, naskah, Jawa

\section{SERAT WEDDHAKARANA: THE GUIDANCE TO ACHIEVE DESIRED BASED ON JAVANESE CULTURE}

\author{
Rahma Qori Fadzilah and Venny Indria Ekowati
}

Prodi Pendidikan Bahasa Jawa, Fakultas Bahasa dan Seni, Universitas Negeri Yogyakarta rahmaqori10@gmail.com ${ }^{1}$ dan venny@uny.ac.id ${ }^{2}$

\begin{abstract}
This study aims to describe the manuscript, make transcription, make transliteration and present text edits, and make text translations. In addition, it also describes the hunch knowledge contained in the Sêrat Weddhakarånå text. This research was conducted using descriptive methods and modern philology. The data source of this research is the Sêrat Weddhakarånå manuscript which is stored in Balai Bahasa Yogyakartalibrary, with collection number R00762. Data collection techniques were carried out in
\end{abstract}


several steps, namely 1) inventory of manuscripts, 2) description of manuscripts, 3) transcription of texts, 4) transliteration, 5) edits, 6) translations, and 7) meaning of texts. The data were analyzed using descriptive analysis techniques. Data validity was done using semantic validity. Reliability was used, namely interatter and intraratter. However, in this article the results of philological research were not conveyed in full because of the page limitations. The results of the study of the Sêrat Weddhakarånå manuscript showed that the condition of the Sêrat Weddhakarånå manuscript is still well maintained, the writing is clear, and it is easy to read. The contents of Sêrat Wéddhåkaråna based on the results of the study were as follows: there are reasons for the achievement of desires that are wanted, thought and carried out. In addition, in order for this wish to be realized, there are several things that must be maintained and cultivated according to Sêrat Wéddhåkarånå namely health, science and skills, and good character. Some of these things must be done together, so that the desired wishes can be realized. The latter are 2 ways to achieve glory and luck according to Sêrat Wéddhåkarånå. The first according to the occult is that because the glory and good luck are the result of an act that has been passed before, which is called lucky is to get something that is not from the results of the act in its path - it is an unexpected gift. So, if humans don't get luck and glory they can't complain. The latter is the reason for the glory and good fortune that is derived from good character. The good character like being diligent, being careful in acting, being smart and can be good in associating with others. Sixth, it discusses the reasons for the achievement of desires - how to realize the desires and the procedures for achieving good fortune and glory.

Keywords: Sêrat Wéddhåkarånå ${ }_{s}$ wishes, manuscripts, Java.

\section{PENDAHULUAN}

Masyarakat Jawa adalah salah satu suku yang meninggalkan kebudayaan yang beraneka ragam. Kebudayaan tersebut masih dilestarikan keberadaanya sampai saat ini. Peninggalan budaya Jawa jumlahnya cukup banyak. Peninggalan yang berupa warisan budaya itu dapat berupa peninggalan yang tidak tertulis seperti candi dan peninggalan tertulis berupa naskah. Naskah merupakan salah satu karya sastra peninggalan kebudayaan yang menojol. Naskah dalam bahasa Inggris disebut manuskrip dan dalam bahasa Belanda disebut handschrift adalah semua peninggalan tertulis nenek moyang pada kertas, lontar, kulit kayu, dan rotan (Djamaris, 1977: 20).

Naskah menjadi salah satu karya sastra peninggalan kebudayan yang memuat beraneka ragam pengajaran, seperti adat istiadat, sejarah, agama, ajaran hidup, dan lain sebaginya. Hal-hal yang terkandung didalam naskah dapat bermanfaat untuk bekal hidup masyarakat. Naskah Jawa sebagian masih berwujud naskah yang berhuruf Jawa, Arab dan sebagian lagi sudah ada yang dialihaksarakan ke tulisan Latin. Apabila naskah Jawa masih berwujud naskah yang berhuruf Jawa atau Arab, masarakat umum tentu susah untuk mengetahui isi naska tersebut. Maka dari itu naskah Jawa perlu dilestarikan. Untuk melestarikan naskah diperlukan ilmu filologi. Melalui ilmu filologi bisa menjadi lantaran upaya melestarikan peninggalan kebudayaan yang berupa naskah. 
Selain itu penelitian dengan ilmu filologi merupakan upaya untuk menyelamatkan naskha Jawa dari kerusakan. Karena apabila naskah telah hancur karena umurnya sudah tua, maka akan kesulitan untuk mengetahui ajaran nenek moyang yang terdapat dalam naskah.

Setiap ilmu tentu terdapat objek penelitiannya, naskah dan teks merupakan objek penelitian filologi (Mulyani,2014). Naskah yang digunakan dalam penelitian ini adalah naskah Sêrat Wéddhåkarånå. Naskah Sêrat Wéddhåkarånå merupakan naskah cetak yang ditulis dalam bahasa Jawa baru dan disampaikan dalam bentuk prosa. Naskah Sêrat Wéddhåkarånå tersimpan di Perpustakan Balai Bahasa Yogyakarta dengan nomor kodeks R00762. Isi naskah Sêrat Wéddhåkarånå terbagi menjadi lima bab, yaitu 1)sebab-sebab tercapainya keinginan, 2) terwujudnya keinginan, 3) sebabsebab keberuntungan dan kesialan, 4) kesanggupan menerima hasil dari perbuatannya sendiri dan 5) cara meraih kebaikan nantinya. Yang dijadikan sumber data penelitian adala bab satu sampai bab tiga, karena bab tersebut yang memuat tata cara meraih keinginan dimana yang menjadi pokok pembahasan dalam penelitian.

Ada beberapa alasan pemilhan naskah Sêrat Wéddhåkarånå dijadikan sumber data penelitian, yang pertama naskah Sêrat Wéddhåkarånå belum pernah ada yang meneliti. Yang kedua, isi dari naskah Sêrat Wéddhåkarånå menarik perhatian karena memuat pengajaran tentang tata cara meraih keinginan yang bisa berguna bagi masyarakat umum. Yang ketiga, wujud naskah Sêrat Wéddhåkarånå masih masih utuh dan masih baik, tulisan naskah masih jelas dan lembar naskah masih utuh. Yang keempat, tulisan naskah Sêrat Wéddhåkarånå berbentuk cetak, sehingga memudahkan dalam membaca isi naskah. Yang kelima, naskah Sêrat Wéddhåkarånå merupakan naskah yang tersimpan di Perpustakaan Balai Bahasa Yogyakarta, dimana lokasinya lebih dekat dengan peneliti.

\section{METODE PENELITIAN}

Metode penelitian yang digunakan dalam penelitian ini menggunakan metode penelitian filologi modern dan metode penelitian deskriptif. Metode penelitian filologi modern digunakan untuk meneliti objek kajian yang berupa naskah dan teks. Metode penelitian filologi digunakan sebagai dasar dalam melakukan langkah kerja penelitian terhadap naskah Sêrat Wéddhåkarånå. Metode penelitian deskriptif bertujuan untuk 
mengumpulkan informasi mengenai seluk beluk Sêrat Wéddhåkarånå. Metode deskriptif adalah salah satu cara untuk meneliti salah satu objek dengan tujuan membuat gambaran dengan objektif dan sistematis yang berhubungan dengan fakta (Kaelan, 2005).

Penelitian ini merupakan perpaduan antara metode penelitian deskriptif dengan metode penelitian filologi. Teknik pengumpulan data menggunakan metode penelitian filologi. Langkah penelitian filologi dalam penelitian ini adalah 1) inventarisasi naskah, 2) deskripsi naskah, 3) transkripsi teks 4) transliterasi teks, 5) suntingan teks, 6) terjemahan teks dan 7) analisis teks. Inventarisasi naskah adalah mengumpulkan informasi tentang dimana saja naskah-naskah yang mengandung teks sekorpus (Karsono:2008). Langkah selanjutnya adalah deskripsi naskah dengan tujuan menggambarkan keadaan naskah dengan sebenar-benarnya. Langkah yang ketiga adalah transkripsi teks, transkripsi teks adalah menyalin kembali teks Sêrat Wéddhåkarånå tanpa mengganti jenis aksara teks (Baroroh-Baried :1985).

Selanjutnya adalah transliterasi teks, transliterasi adalah penggantian jenis tulisan, huruf demi huruf, dari abjad yang satu ke abjad yang lain (Baroroh-Baried :1985). Transliterasi teks dilakukan dengan cara mengganti jenis aksara, yaitu dari aksara Jawa ke aksara Latin. Transliterasi dilakukan dengan tujuan untuk memudahkan dalam membaca teks.

Langkah yang kelima adalah suntingan teks, dalam penelitian inisuntingan yang digunakan adalah suntingan dengan edisi standar. Suntingandengan edisi standar dalam penelitian ini dibuat agar masyarakat dapat membacanaskah Sêrat Wéddhåkarånådengan mudah. Dalam suntingan teks diperlukan tanda-tanda untuk memperjelas bagianbagian teks yang disunting.

Setelah suntingan teks, langkah yang selanjutnya adalah terjemahan teks. Terjemahan adalah suatu langkah dalam kajian filologi yang berupa penggantian bahasa naskah ke dalam bahasa lain, misalnya saja dari bahasa Jawa ke dalam Bahasa Indonesia. (Rokhmansyah : 2017) mengatakan tujuan dari terjemahan ini adalah untuk memudahkan pembaca untuk mengetahui isi teks. Langkah yang terakhir adalah analisis

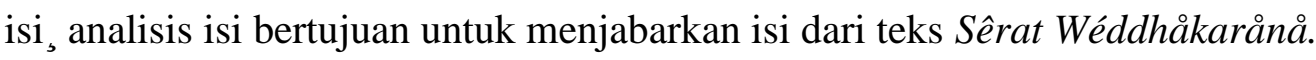

Instrumen yang digunakan dalam penelitian ini berupa kartu data. Kartu data digunakan untuk mencatat data-data yang sesuai dengan kebutuhan penelitian, yaitu 1) 
inventarisasi naskah 2)deskripsi naskah, 3) transkripsi teks 4) transliterasi dan suntingan teks, 3) aparat kritik, 4) terjemahan teks, dan 5) analisis isi. Setiap satu kesatuan konsep data dicatat pada tabel sesuai dengan kategorinya.

Analisis data dilakukan dengan analisis deskriptif kualitatif. Cara analisis data dilakukan dengan empat tahapan, yaitu (1) reduksi data, (2) klasifikasi data, (3) display data, dan (4) penafsiran dan interpretasi data (Kaelan : 2005).

Pengesahan data dilakukan dengan validitas semantik dan reliabilitas. Validitas semantik yaitu memaknai kata-kata dan kalimat berdasarkan konteksnya. Tahap reliabililtas terbagi menjadi dua, yaitu reliabilitas intrarater dan reliabilitas interrater. Reliabilitas intrarater dilakukan dengan membaca teks berulang-ulang untuk memperoleh data yang tetap dan konsisten. Reliabilitas interatter dilakukan dengan melakukan verifikasi data kepada ahli filologi.

\section{HASIL DAN PEMBAHASAN}

Hasil dan pembahasan pada makalah ini difokuskan pada pembahasan isi naskah, karena keterbatasan tempat. Sedangkan hasil secara filologis disajikan dengan terbatas. Berikut ini disampaikan secara singkat, hasil penelitian yang telah dilakukan.

Keadaan naskah Sêrat Wéddhåkarånå masih baik dan utuh. Tidak ada lembar yang sobek dan rusak. Tulisan masih bisa terbaca dengan jelas. Tinta yang digunakan berwarna hitam dan tercetak tipid. Kertas yang digunakan adalah kertas hvs, dan jilidan masih terlihat kuat. Terdapat 64 halaman, dan setiap halaman rata-rata terdapat 21 baris. 1. Pembahasan tentang sebab-sebab tercapainya keinginan

Setiap manusia tentu mempunyai keinginan yang diidam-idamkan. Dalam meraih keinginan tersebut ada hal-hal yang harus dilakukan. Dibawah ini ada tiga perkara sebab-sebab tercapainya keinginan.

Gambar 1. Sebab-Sebab Tercapainya Keinginan

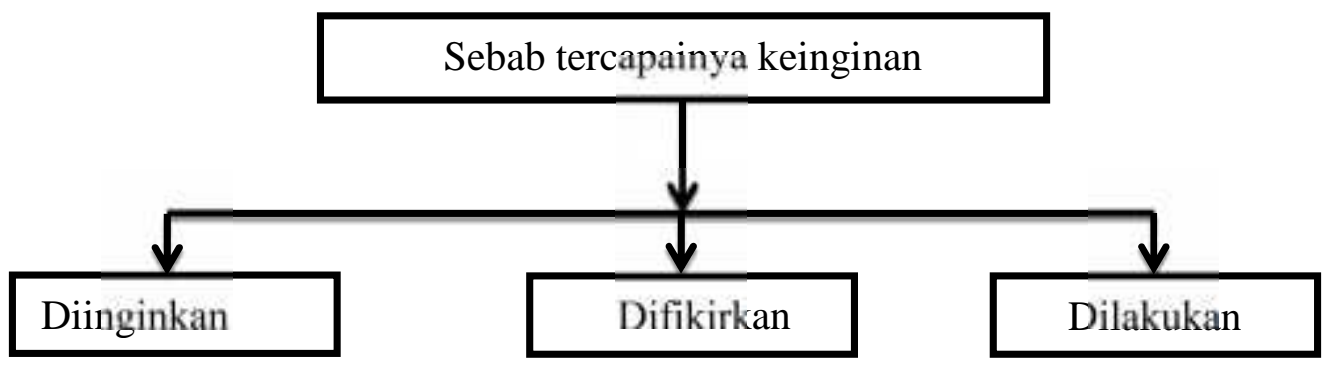


Seperti yang sudah disebutkan diatas, ada tiga hal yang harus dilakukan ketika ingin meraih keinginan. Kutipan mengenai hal tersebut terdapat dalam Sêrat Wéddhåkarånå seperti dibawah ini.

saénipun nindakakên sabarang damêl punikå kêdah alêbêtakên ing manah. Dipunpandang wontên ing kajêng, dipunpindêng wontên ing ciptås dipuntalatosi ing pagarapipun.

\section{Terjemahan:}

ada baiknya ketika melaksanakan pekerjaan apapun harus dengan hati diamati terlebih dahulu, dipikirkan saat melaksanakan, dan harus telaten saat mengerjakan.

Dalam meraih keinginan yang pertama harus dilakukan adalah benar-benar mengetahui apa yang sebenarnya diinginkan. Maksudnya ${ }_{s}$ jika sudah mengetahui apa yang benar-benar diinginkan, maka yang harus dilakukan adalha merancang strategi agar keinginan tersebut dapat tercapai. Seperti yang dijelaskan oleh Musman, (2017) bahwa merancang atau mempunyai tujuan itu digunakan untuk membuat strategi yang digunakan untuk meraih keinginan.

Langkah selanjutnya adalah difikirkan. Apapun keinginannya apabila hanya diinginkan dan tidak dipikirkan pasti tidak akan terwujud. Keinginan tersebut harus difikirkan dengan baik, dan harus mempunyai pemikiran yang baik. Pemikiran manusia itu terbagi menjadi dua, yaitu pemikiran yang positif dan negatif. Dengan pemikiran yang positif maka semua hal yang dilakukan akan terlaksana walaupun susah dalam pelaksanaanya. Berbeda kalau mempunyai pemikiran yang negatif, apabila sudah mempunyai pemikiran yang negatif maka semua hal yang semestinya bisa dilaksanakan akan menjadi susah dalam mewujudkannya, Maltz (melalui Musman:2017).

Sebab tercapainya keinginan yang terakhir adalah dikerjakan. Apabila sudah diinginkan, difikirkan, langkah selanjutnya adalah eksekusi. Keinginan apapun itu apabila tidak dikerjakan maka keinginan tersebut tidak akan bisa tercapai. Walaupun dalam pengerjaan dilakukan dengan sedikit demi sedikit, tetapi harus telaten. Karena apabila sudah berusaha dengan sungguh-sungguh maka Tuhan akan memberi pertolongan. 
2. Pembahasan tentang Terwujudnya Keinginan

Gambar 2. Terwujudnya Keinginan

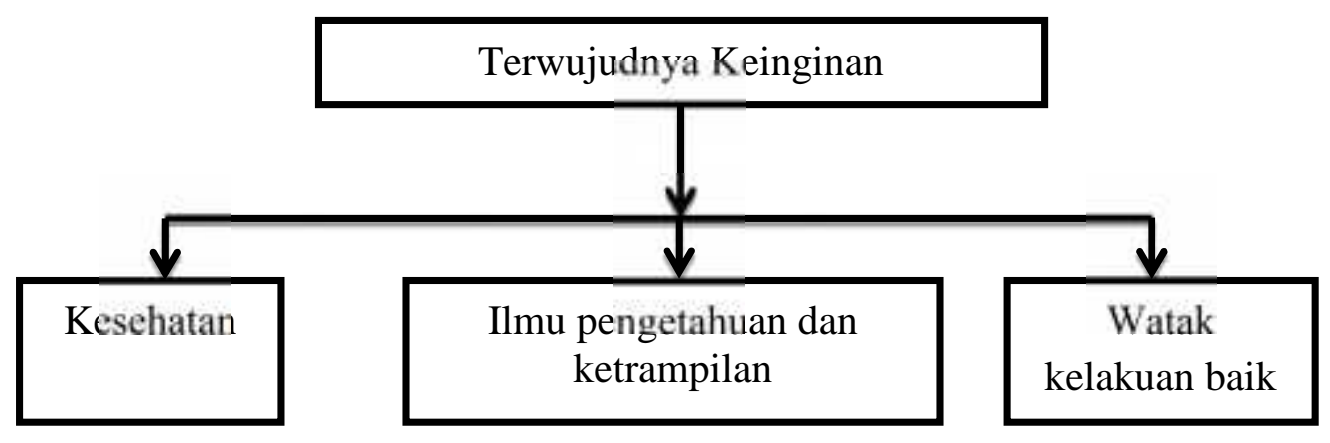

Terdapat tiga syarat agar manusia dapat mewujudkan keinginannya. Ketiga hal tersebut tidak hanya harus dimiliki, tetapi juga harus dilakukan bersama-sama. Syarat yang pertama adalah kesehatan. Untuk meraih keinginan tentu membutuhkan tubuh yang sehat agar segala hal yang dikerjakan dapat dengan maksimal. Hal tersebut terdapat dalam Sêrat Wèddhåkarånå yang kutipannya seperti dibawah ini.

Kasarasan punikå kajawi kanggé kikiyatan kumrêkat tumandang garap pandamêlan ingkang sêdya dipunlampahi, inggih kanggé anjangkêpakên adêgipun prabot ing gayutaning ngagêsang,

\section{Terjemahan:}

Kesehatan diperlukan untuk kekuatan melaksanakan pekerjaan yang dilaksanakan, yaitu agar terlaksananya pekerjaan,

Berdasarkan kutipan diatas, dapat disimpulkan bahwa kesehatan merupan hal yang penting agar pekerjaan yang dilakukan dapat terlaksana dengan lancar. Kesehatan yang dimaksud dalam kutipan di atas tidak hanya kesehatan badan, tetapi juga dkesehtan jiwa. Kesehatan menjadi kebutuan mendasar bagi setiap manusia. Menjaga kesehatan itu wujudnya beda-beda. Contohnya menjaga kesehatan antara anak muda dengan orang tua. Dibawah ini kutipan Sêrat Wéddhåkarånå yang menyebutkan cara menjaga kesehatan.

Ulah kasarasan manawi ing ngatasipun laré utawi tiyang nèn-nemaningkang pêrlu badhé kanggé tumandang anggarap padamêlan ulah kadonyan kados upaminipun ing kajunjung sasaminipun lampahing ulah kasarasan kénging mawi dipunsranani ulah nyolahakên badan ajar karosan, nanging manawi ing ngatasipun tiyang sêpuh ingkang pêrlu badhé ulah kasuksman patraping ulah kasarasan botên makatên, ingkang prayogi dipunlampahi jatmikå alusing budi, ngangkah-angkah ing solah båwås anêntrêmakên ciptå sasaminipun, 
dados patrapipun ulah kasarasan punikå inggih mawi bédå-bédå manut êmpan papan tuwin ningali wahyaning måså kålå, panimbangipun kawatawis ing dugi prayogi kalaras patutipun utawi cundhukipun.

\section{Terjemahan:}

Kesehatan apabila pada anak atau orang-orang muda yang diperlukan yaitu melaksanakan pekerjaan duniawi seperti menolong sesama, latihan fisik untuk kesehatan dilakukan dengan cara menggerakkan badan sebagai ajang melatih kekuatan. Akan tetapi jika latihan pada orang tua perlu dengan cara yang lembut, jika pada orang tua kegiatan yang dilaksanan berbeda dengan anak muda. Yang baik adalah melaksanakan kegiatan dengan menata pikiran dengan baik, berniat dengan sikap yang baik, menentramkan pikiran terhadap sesama. Jadi penerapan wujud dari kesehatan itu berbeda-beda tergantung kepada siapa wujud kesehatan itu diterapakan, penerapannya terbatas dan juga selaras.

Berdasarkan kutipan diatas dapat diketahui bahwa menjaga kesehatan itu harus dengan cara yang tepat. Menjaga kesehatan bagi anak muda bisa dengan melakukan pekerjaan. Dengan bekerja bisa menjadikan badan menjadi sehat. Wujud kesehatan dari orang tua adalah dengan menjaga hati dan pikiran dengan baik. Caranya dengan berfikir masak-masak sebelum melakukan suatu pekerjaan. Kemudian setiap peristiwa dan kejadian jangan semua dimasukkan ke dalam hati, karena hati dan pikiran manusia itu tidak jelas batasnya tetapi ada batasnya. Artinya bahwa manusia hidup harus berhatihati karena hidup di dunia itu hanya sementara (Endraswara, 2016).

Selanjutnya adalah ilmu pengetahuan dan ketrampilan. Ilmu pengetahuan dan ketrampilantentu diperlukan untuk meraih keinginan, karena dengan ilmu pengetahuan dan ketrampilan merupakan sarana untuk meraih keinginan. Hal tersebut terdapat dalam kutipan teks Sêrat Wéddhåkarånå seperti dibawah ini.

Kawruh kasagêdan punikå ${ }_{s}$ kajawi kanggé dadamêl ing gagayuh kabêgjan ing marcåpådå utawi kamulyaning dêlahan, inggih kanggé dadamar sartå kaprigêlan utawi ririgêning ulah kasarasan såhå ulah watak kalakuwan saé, awit manawi tanpå kawruh kasagêdan saèstu susah kawontênanipun.

Terjemahan:

Pengetahuan kemampuan itu selain untuk meraih keinginan agar bahagia di dunia atau kemuliaan di akhirat, juga untuk penerangan serta ketrampilan dan juga melaksanakan watak kelakuan baik, karena tanpa pengetahuan dan kepandaian jelas tentu susah. 
Berdasarkan kutipan diatas, disebutkan bahwa manusia hidup di dunia memerlukan ilmu pengetahuan dan ketrampilan. Dengan ilmu pengetahuan dan ketrampilan manusia dapat mencapai keinginan dan hidup dengan mulia. Manusia yang menginginkan kemuliaan dunia harus mencari ilmu yang digunakan di dunia. Apabila orang yang mencari kemuliaan akhirat maka harus mencari ilmu yang digunakan untuk meraih kemuliaan akhirat. Hal tersebut terdapat dalam kutipan teks Sêrat Wéddhåkarånå seperti dibawah ini.

Ulah kawruh kasagêdan, manawi ing ngatasipun tiyang ulah kadonyan inggih kêdah pados kawruh ingkang pancèn kanggé ing donyå kadostå :

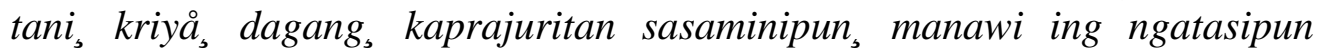
tiyang ingkang ngudi kamulyaning dêlahan inggih kêdah pados kawruh ingkang pancèn kanggé ing dêlahan kadostå : kawruh lampahing pangastuti, kawruh pamanguning wawatakan

\section{Terjemahan:}

Ulah ilmu tentang kemampuan, apabila orang yang mementingkan duniawi harus mencari pengetahuan yang pasti digunakan di dunia, seperti bertani, bertukang, berdagang, kepegawaian dan sebagainya, apabila orang yang lebih mementingkan kemuliyaan di akhirat, harus mencari ilmu yang memang pasti digunakan di akhirat, seperti ilmu lampahing pangastuti , $_{\text {, }}$ lmu membangun watak.

Dari kutipan diatas s bisa dimengerti bahwa meraih kemuliaan dunia dan akhirat itu membutuhkan ilmu. Manusia hidup di dunia harus mencari bekal agar hidupnya bisa meraih kemuliaan. Apabila di dunia manusia hidup mencari bekal berupa sandang dan pangan. Akan tetapi manusia hidup didunia juga harus menerapkan laku prihatin. Laku prihatin diperlukan untuk melatih jiwa dan raga supaya bisa mudah dalam melalui situasi apapun. Laku prihatin berubungan dengan Tuhan, yang artinya bahwa manusia hidup didunia nantinya akan kembali kepada Tuhan (Endraswara :2016).

Yang terakhir adalah watak dan kelakuan baik. Setiap manusia tanpa terkecuali harus mempunya watak dan kelakuan yang baik. Seperti dalam kutipan Sêrat Wéddhåkarånådibawah ini.

Watak kalakuan saé punikå kajawi kanggé saéning pasrawungan inggih kanggé gêsau sagêd angréh ciptå mêkahåwå napsunipun piyambak, tiyang sagêd dipunwidå damanggih kasarasan punikå kêdah saé watak kalakuwanipun jêjêg ciptanipun, watak kalakuan awon såhå ciptå awon punikå gampil sagêd dipunnuwuhakên sasakit kathah båyå pakéwêddå ingkang sumandhing, dados cêpak bilahinipun, tiyang sagêd dipunangêmpak kawruh kasagêdan dhatêng tiyang sanès utawi saged dipunangêmpakakên 
pamrih punåpå kémawon ingkang mawi sarånå gagayutan kaliyan tiyang sanés sampun tamtu kêdah kanthi kadhasaran watak kalakuwan saé, jêjêg ci[15]ptaning, manawi botên makatên sampun têmtu, kangèlan kalampahaning sêdyånipun.

\section{Terjemahan:}

Watak dan kelakuan baik selain untuk kehidupan bersosial yang baik , yaitu juga untuk melaksanakan perbuatan baik dan menjauhi hawa nafsu sendiri. Orang yang sehat harus mempunyai watak dan kelakuan yang baik serta keinginan kuat. Watak, kelakuan, dan keinginan buruk sangat mudah menimbulkan penyakit serta banyak halangan yang mengiringi, jadi mudah mendapat kesialan, orang bisa didekatkan pengetahuan kepada orang lain atau bisa didekatakan dengan tujuan apapun melalui sarana orang lain tentu harus berdasarkan watak kelakuan baik dan keinginan yang kuat, jika tidak demikian sudah pasti kesusahan melaksanakan semuanya

Berdasarkan kutipan diatas dapat dimengerti bahwa manusia hidup didunia harus mempunyai kebaikan terhadap sesama makhluk. Watak kelakuan baik dapat berupa menjaga kerukuan terhadap siapa saja. Hidup di dunia memerlukan pertolongan dari orang lain dan tidak dapat hidup sendiri.

Watak dan kelakuan baik dibutuhkan untuk meraih kemuliaan dunia dan kemuliaan akhirat. Seperti yang terkandung dalam teks Sêrat Wéddhåkarånå kutipannya seperti dibawah ini.

Ulah watak kalakuan saé, manawi ing ngatasipun tiyang ingkang namung milulu ulah kadonyan : anggêr nåmå ngidak kilêrês lan saé, kadosta : nyirnakakên watak angkårå murkå ${ }_{3}$ nistha, kaniåyå ardå puwå puwå sasaminipun inggih sampun kacêkap, nanging manawi tiyang ingkang sêdyå anggayuh kamulyaning dêlahan utawi sampurnaning panungêl kêdah mawi angingircingi dhatêng sadåya kakajêngan ingkang tujunipun dhatêng kadonyan mèpèt napsu håwå. ngipatakên pakarêman mêjahi pèpènginan sasaminipun.

Terjemahan:

Ulah watak kelakuan baik, apabila ada orang yang hanya memikirkan duniawi : setiap orang melakukan hal baik seperti menghilangkan watak angkara murka, jelek, sewenang-wenang, hawa nafsu, terhadap sesama sudah cukup, apabila ada orang yang mempunyai niat meraih kemuliaan akhirat atau sempurnanya hidup, harus mau menjauhi semua keinginan yang tujuannya untuk duniawi dengan mengerem hawa nafsu, membuang keinginan. 
Berdasarkan kutipan di atas dapat disimpulkan bahwa watak kelakuan baik antara manusia yang menginginkan duniawi dengan manusia yang menginginkan akhirat itu berbeda. Apabila manusia yang lebih menginginkan keduniaan harus melakukan perbuatan yang baik dan menyingkirkan perbuatan yang buruk. Akan tetapi apabila orang yang ingin meraih kemuliaan akhirat, tidak hanya melakukan perbuatan baik dan mengindari perbuatan buruk saja, tetapi harus menyingkirkan semua keinginan yang berhubungan dengan keinginan duniawi.

3. Meraih kemuliaan dan keberuntungan

Manusia tentu mempunyai keinginan supaya dalam hidupnya bisa meraih kemulian dan keberuntungan. Tentunya agar hidup kita bisa mulia dan menemui keberuntungan, memerlukan beberapa syarat. Sêrat Wéddhåkarana memuat mengenai syarat untuk meraih kemuliaan dan keberuntungan. Pembahasan mengenai hal tersebut dibagi menjadi dua, yaitu bab gaib atau samar dan menurut penalaran.

a. Menurut bab gaib

Untuk meraih kemuliaan hidup, manusia tentu harus melaksanakan perbuatanperbuatan yang bisa menyebabkan hidup mulia. Menurut penjelasan dalamSêrat Wéddhåkarånå disebutkan seperti kutipan dibawah ini.

pintên-pintên kamulyanutawi kauntungan ingkang nyamlêng dados ganjaraning kautaman utawi kasaénan ingkang sampun dipunlampahi.

\section{Terjemahan:}

Beberapa kemuliaanataukeuntungan itu menjadi hadiah dari keutamaan atau kebaikan yang sudah dilakukan

Dari petikan teks diatas, bisa dimengerti bahwa kemuliaan dan keberuntungan dalam hidup, merupakan hadiah dari kebaikan yang sudah kita lakukan sebelumnya. Jadi kita sebagai manusia harus melaksanakan kebaikan, dengan melaksanakan kebaikan bisa menjadikan hidup kita meraih kemuliaan dan keberuntungan nantinya. Hal ini cocok dengan penjelasan Musman (2017), yaitu melaksanakan kebaikan itu sejatinya untuk diri kita sendiri, apabila manusia melakukan kebaikan tentu nantinya juga akan menerima kebaikan juga.

Dengan demikian, manusia hidup didunia harus melakukan kebaikan. Karena perbuatan apapun yang kita lakukan akan ada balasannya. Hal ini juga dijelaskan dalam teks SÊRAT WÉDDHÅKARÅNÅ, seperti dibawah ini. 
kamulyan lan kasangsaran ingkang pinanggih ing sapunikå , punikå wohing pandamêl ingkang sampun-sampun pandamêl ingkang linampah lan ing sakpunikå

\section{Terjemahan:}

kemuliaan dan kesengsaraan yang akan ditemui nantinya, itu semua hasil dari perbuatan yang kita perbuat sejak dahulu hingga sekarang

Tidak hanya melaksanakan kebaikan saja s akan tetapi kita harus menjauhi perbuatan buruk. Hal ini terdapat dalam teks SÊRAT WÉDDHÅKARÅNÅ, kutipannya seperti dibawah ini.

sintên ingkang ndamêl kasaénan tamtu ing wingking manggih pitulungan, milå manungså kêdah ambudi sagêd dipunanyingkiri pandamêl awon lan lêpat såhå ambudi sagêd dipundamêl kasaénan.

Terjemahan:

siapa yang berbuat baik tentu nantinya mendapatkan pertolongan, maka dari itu manusia harus berfikir agar bisa menyingkirkan perbuatan buruk dan salah, serta berfikir agar dapat berbuat baik.

Bagaimana mendapatkan keberuntungan dalam hidup, disebutkan dalamteks SERAT WÉDDHÅKARÅNA, seperti dibawah ini.

ingkang dipunwastani bêejå punikå manggih kauntungan ingkang botên saking wohing pakratinipun piyambak

Terjemahan:

yang dimaksud beruntung yaitu menemukan keuntungan yang bukan dari hasil perbuatan yang telah dilaluinya.

Berdasarkan kutipan di atas, yang dimaksud mendapatkan keberuntungan adalah mendapatkan sesuatu bukan dari hasil perbuatan kita sendiri. Sedangkan kemuliaan merupakan hasil perbuatan kita sendiri, jadi tidak boleh mengeluh jika menerima balasan. Hal ini dijelaskan dalam teks $S W$ seperti dibawah ini.

sêdåyå bêejå cilåkå mulyå sangsårå saking pakartining manungså piyambakpiyambak, dados wajibipun manungså kêdah botên angêrsulå déning manggih sangsårå utawi kapitunan awit sangsårå utawi kapitunan saking lêpatipun piyambak, sartå botên ajrih kécalan kanggè ndamêl kasaénan amargi tamtu 


\section{Terjemahan:}

Semua keberuntungan dan kesialan, mulia dan sengsara berasal dari perbuatan manusia sendiri. Jadi seharusnya manusia tidak boleh mengeluh apabila mendapat kesengsaraan atau kerugian yang berasal dari kesalahannya sendiri.

b. Menurut penalaran

Sebab kemuliaan apabila menurut penalaran, dijelaskan dalam teks SERRAT WÉDDHÅKARÅN̊, kutipannya seperti dibawah ini.

Jalaraning kamulyan punikå saking watak saé kadostå : tabèri, wiwêkå ${ }_{s}$, sugih budi, sagêd saé pitêpanganipun utawi pasrawunganipun kaliyan sasamining ngagêsang.

Terjemahan:

Sebab dari kemuliaan itu berasal dari watak baik, seperti : rajin, berhati-hati, pintar ${ }_{s}$ bisa baik pergaulannya terhadap sesama.

Dari kutipan diatas bisa kita ketahui bahwa meraih kemuliaan itu harus mempunyai watak yang baik. Watak adalah karakter atau tabiat. Sudah disebutkan watak yang baik seperti rajin, rajin dalam melakukan kebaikan. Selanjutnya berhati-hati, maksudnya berhati-hati dalam kehidupan atau orang Jawa sering menyebut sembrana atau seenaknya. Watak dan karakter yang harus dimiliki untuk syarat hidup mulia adalah pintar dan mampu bergaul dengan baik.

\section{SIMPULAN DAN SARAN}

Penelitian ini menyajikan tentang cara-cara meraih keinginan. Yang pertama adalah sebab-sebab tercapainya keinginan ada 3 hal yaitu diinginkan, difikirkan dan dilaksanakan. Yang kedua agar keinginannya terwujud harus melakukan tiga perkara yaitu mempunyai kesehatan, mempunyai ilmu pengetahuan dan ketrampilan, mempunyai watak kelakuan baik, yang terkakhir adalah sebab kemuliaan dan keberuntungan.Penelitian ini merupakan penelitian awal dan selanjutnya dapat membuka kesempatan bagi peneliti yang lain untuk meneliti naskah Sêrat Wéddhåkarånå dengan fokus kajian yang berbeda.

\section{DAFTAR PUSTAKA}

NN. Sêrat Wéddhåkarånå. Perpustakaan Balai Bahasa Yogyakarta, nomor koleksi R00762 
Baroroh-Baried, Siti dkk. (1985). Pengantar Teori Filologi. Jakarta: Pusat Pembinaan dan Pengembangan Bahasa Departemen Pendidikan dan Kabudayaan.

Djamaris, Edwar. (2002). Metode Penelitian Filologi. Jakarta: CV Manasco.

Endraswara, Suwardi. (2006). Falsafah Hidup Jawa. Yogyakarta: Penerbit Cakrawala.

Kaelan. (2005). Metode Penelitian Kualitatif Bidang Filsafat. Yogyakarta: Paradigma.

Mulyani, Hesti. (2014). Teori dan Metode Pengkajian Filologi. Yogyakarta: Astungkara Media.

Musman , Asti. (2017). Pitutur Luhur Jawa Ajaran Hidup dalam Serat Jawa. Yogyakarta : Pustaka Jawi.

Rokhmansyah, Alfian. (2017). Teori Filologi. Yogyakarta : CV. Istana Agency.

Saputra, Karsono. (2008). Pengantar Filologi Jawa. Cetakan Pertama. Jakarta : Wedatama Widya Sastra. 